\title{
Child surveillance in Ireland
}

\author{
Aimie Brennan \\ School of Sociology and Philosophy, UCC
}

\section{Introduction}

Ten year old James looks out the backseat car window. He's familiar with the views and with speaking to his mom through the gap in the seat. For a moment he wonders what it would be like if it was different. Sometimes he would like to stay at home and play with his dog or cycle his new bike to soccer training. He's used to having his mom drive him. . . but its boring. Then he thinks; what if a car knocks him down? What if a stranger talks to him? What if he gets lost? No, its much better this way, isn't it?

Could James' experience be a memory from your childhood? Maybe not but my research would suggests that this is becoming a more common experience. The rapid globalisation of Ireland in recent years has hugely impacted many aspects of family life especially the lives of children, for many reasons; the return of women to work, the increase in financial resources, the decrease in public space. International research has shown that in countries which have experienced rapid globalisation like Ireland, children, are experiencing major changes. This paper focuses on just one aspect of these changes that is; freedom and mobility (children's independent movement from place to place). I argue that the current behaviour surrounding children's supervision may be having a negative impact on children and family life.

\section{What happened in other countries?}

In the UK, Amsterdam and the USA researchers have found that children's independent mobility has decreased since the 1970's. In the UK, Valentine (1997) examined children's outdoor play, finding that fewer children were playing outdoors. Fotel and Thomsen supported this, finding that almost $100 \%$ of parents admitted to restricting their children's outdoor play. The result was that children's play had become much less street-based and more home-centered. The movement of children from the street to indoors changed the kinds of games that children play.

Valentine (1997) found that children began to take part in more organized activities. Two thirds of the children in the UK participated in some form of organised activity. In urban areas especially, these activities such as horse riding, dancing, rugby etc. take place in 


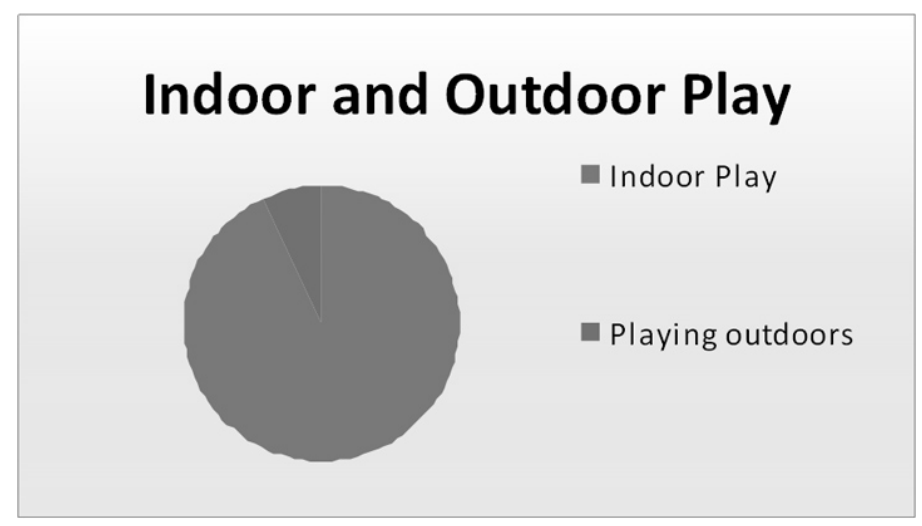

Figure 1: The percentage of time children spend playing indoors and outdoors

locations quite a distance from the child's home, so driving becomes the preferred method of transport. In 1990, Hillman called these children, who were chauffeured from place to place, 'backseat children'. Similar to 'indoor children', the backseat child experienced decreased independent mobility and increased supervision by adults. That is, they rarely used methods of transport such as walking or cycling, which they could do unsupervised. Alder and Alder found that class was a major determinant of children's leisure experiences. For example, the chauffeuring practice of the backseat generation was only relevant to those who own a car, and those who have the time to transport the child. So 'backseat children' were predominantly found to be middle-class children.

\section{My research findings:}

In order to examine whether or not middle class children in Ireland were experiencing similar practices to the backseat child and the indoor child I interviewed approximately 756 to 10 year-old children and their parents in Cork City. From preliminary analysis, it would seem that Irish middle class children are experiencing similar trends to the UK and USA. Characteristics of both the backseat child and the indoor child have begun to emerge from my data.

\section{The indoor child}

Middle class children's play has become much more home centred, either outdoor in a private garden or indoors. The chart below represents how the middle class children I interviewed spend their unstructured time, that is their weekends and after-school time. According to the parents I spoke to, during this unstructured time their children are always supervised by an adult. This includes any time they may spend playing in the street or green. 


\section{The Backseat child}

The increased involvement of parents in children's after school hours has led to their increased involvement in structured activities. All the parents I interviewed agreed that structured activities are beneficial to children socially and physically and they also keep children safe. They claimed that their children had a busy lifestyle. This applied to children from as young as 6 up to 10 years old. Below is a chart indicating the number of structured activities in which the children participate on a weekly basis.

The high volume of activities in which children participate inevitably brings them all over the city. Over $60 \%$ of families indicated that the activities were not local and involved traveling up to 3 kilometers to at least one activity per week. Families who had more than one child attending such activities spent a lot of time in the car.

\section{Why have we increased supervision?}

It is understandable that parents are anxious about their child's safety. However, the issue of safety and risk has changed. New global risks are circulated by the media on a daily basis which increase parental anxiety amongst the middle-classes. Stories like that of Madeline McCann have become common knowledge. One method of negotiating these risks is to increase supervision. Parents feel less anxious if they know where their child is, or if they are with a responsible adult. Parents make more of an effort to create situations where their child is in this position. There is no question that their intentions are good. The problem arises when children are in adult care all of the time. It is adults' over-involvement in children's leisure activities that has led to the creation of these new 'childhoods'; the indoor child and backseat child.

\section{Possible consequences of increased supervision}

Although there are positive elements to attending structured activities and it is safer to drive children long distances, the extent to which some children are being supervised is excessive. Parents are taking full responsibility for protecting their children all of time. This is stressful and almost impossible. I presented the children with the following scenarios

What would you do if you were at home alone and there was a knock on the door?

How do you cross the road safely?

What would you do if you were walking to school and a stranger started talking to you? 
There was a sense of nervousness and an initial response of 'I don't know'. Subsequently, I received one of two responses. Some children recited contrived answers they had learned in school. The others, mostly the younger ones, created a plan of action whereby they would badly injure the stranger, or escape in a very elaborate way. While I can appreciate that some of these scenarios would be quite frightening, their answers didn't fill me with confidence. It is possible that many of the children really couldn't handle facing these risks.

I also asked them if they would like to spend more time at home alone, playing in their room or outside and, unexpectedly, $85 \%$ of them said no. They explained that they would be too frightened. Afraid of the phone ringing or a knock on the door, afraid of the kettle or the oven and more seriously afraid of robbers or stalkers! Some parents even told me that children would panic if they were left alone for too long. It seems to be the case that the risks and anxieties of their parents, and society at large, are being absorbed by these middle-class children. Will these children always be nervous? Will they be able to negotiate risks later in life or will they remain dependant on others?

Some psychologists suggest that the over-involvement of parents in children's lives has detrimental effects on children's development. The French psychologist Piaget accredits a child's intelligence to its participation with its environment. Outdoor play presents children with the opportunity to be creative and to interact with their environment. I can remember making up games, changing the rules or inventing new ones. When children have to decide on a location for their game, at time to meet, a type of game and a set or rules which will be used they are developing many skills such as problem-solving. As early as the 1970s, it was noted that children's spontaneous play encouraged the development of interpersonal skills. Unfortunately these new highly supervised, structured childhoods of the backseat child and the indoor child deter this kind of play in the interest of child safety.

\section{Conclusion}

This paper has highlighted children's need for space, freedom and independent mobility. The new childhoods which I have found to exist in Ireland are not providing for this need and, as a result, Irish children are experiencing problems similar to other globalized countries such as the USA and the UK. It has been suggested that these behaviours are class-based; therefore, in order to understand the causes and consequences of this behaviour in greater depth, my research will be expanded to examine supervisory patterns of both advantaged and disadvantaged families in Ireland.

Aimie Brennan is a Student in the School of Sociology and Philosophy under the supervision of Dr. N. Hourigan. The author would like to acknowledge funding from the College of Arts, Celtic Studies and Social Science in UCC. 